OPEN ACCESS

Edited by:

Rochelle Diane Seitz, College of William \& Mary,

United States

Reviewed by:

Andrew D. Thaler,

Blackbeard Biologic Science and Environmental Advisors,

United States

Andrew M. Fischer,

University of Tasmania, Australia

*Correspondence:

Elena Buscher

ebuscher@uvic.ca

Specialty section:

This article was submitted to

Marine Conservation

and Sustainability,

a section of the journal

Frontiers in Marine Science

Received: 18 April 2020

Accepted: 22 July 2020

Published: 13 August 2020

Citation:

Buscher E, Mathews DL, Bryce C, Bryce K, Joseph D and Ban NC (2020) Applying a Low Cost, Mini Remotely Operated Vehicle (ROV) to Assess an Ecological Baseline of an Indigenous Seascape in Canada. Front. Mar. Sci. 7:669. doi: 10.3389/fmars.2020.00669

\section{Applying a Low Cost, Mini Remotely Operated Vehicle (ROV) to Assess an Ecological Baseline of an Indigenous Seascape in Canada}

\author{
Elena Buscher ${ }^{*}$, Darcy L. Mathews ${ }^{1}$, Cheryl Bryce ${ }^{2}$, Kathleen Bryce'2, Darlene Joseph ${ }^{2}$ \\ and Natalie C. Ban ${ }^{1}$
}

${ }^{1}$ School of Environmental Studies, University of Victoria, Victoria, BC, Canada, ${ }^{2}$ Songhees Nation, Victoria, BC, Canada

Marine ecosystems are facing unprecedented threats. Baseline information about the state of ecosystems is needed to address these threats. Ecosystem assessments can be completed over varying scales through different methodologies or a combination of them. Despite these many technologies, most marine environments lack comprehensive habitat assessments. Remotely operated vehicles (ROVs) provide an opportunity to conduct small- to meso scale ecological surveying without some of the constraints of commonly used methodologies such as scuba. The development of cost-effective models of ROVs broadens the accessibility of this technology to many different user groups. We applied the Trident ROV as part of a community-based research project to conduct marine conservation planning around the Tl'ches archipelago with the Songhees Nation in Victoria, British Columbia. We had two main objectives: (1) We evaluated the marine ecological data collection capabilities for the Trident OpenROV and (2) our surveys aimed to complete a systematic benthos classification and document the algal community as well as document a baseline of Songhees culturally important species. We also discuss evaluated the ability of the Trident to provide high resolution ecological data to inform a marine use planning process. We found the Trident to be a capable tool to conduct systematic marine surveying despite some limitations such as low maneuverability in moderate to high current environments and dense kelp areas. We were able to document 14 of 25 culturally important species and 28 species of algae and seaweeds. We were also able to identify highly stressed environments suited for future restoration efforts. The application of a mini low cost ROV to inform marine use planning generated high-resolution data that enabled the Songhees Nation to confirm the whole archipelago warrants protection and necessitates the exclusion of non-Indigenous user groups. Documenting and having a permanent record of the substrate, algal cover, and culturally important species composition around the seascape Tl'ches could serve as one reference point for the Songhees Nation to establish a monitoring system.

Keywords: indigenous governance, marine conservation, indigenous conservation, remotely operated vehicle, baseline assessment 


\section{INTRODUCTION}

Marine ecosystems are faced with many threats such as climate change, ocean acidification, overfishing, increased shipping traffic (Myers and Worm, 2003; Worm et al., 2006; Ban et al., 2010; Kroeker et al., 2013; Seebens et al., 2013; Cheng et al., 2019), and therefore resource managers and policy-makers alike need information about the state of a system in order to formulate meaningful management direction and have a baseline against which to assess it (Gaydos et al., 2008; Berkes, 2015). Ecological baselines can be established through systematic ecological surveying or through other methods, such as interviews with users of the marine environment (Moller et al., 2004; Eckert et al., 2018). Baselines of ecological variables are shifting via generational or personal forgetfulness through time (Pauly, 1995; Papworth et al., 2009). Despite this, recent marine historical ecology work has shown that baselines can be extended backwards over decades through interviews with knowledge holders and users of the local marine environment (Eckert et al., 2018), and over centuries and millennia through archeological means (McKechnie et al., 2014). Ecological baselines are an essential precursor to monitoring programs to be able to judge change in a given ecosystem and subsequently counteract ecological degradation by establishing conservation measures (Magurran et al., 2010).

Marine ecosystems can be assessed through monitoring and mapping benthic habitats to varying scales (Diaz et al., 2004; van Rein et al., 2009). To assess habitat composition of broadscale marine ecosystems $(>1 \mathrm{~km})$, single beam, side-scan or high resolution multibeam sonar are typically used for mapping the physical aspects of the ocean floor at all depths (Greene et al., 1999; Diaz et al., 2004; Rooper and Zimmermann, 2007; Pacunski et al., 2008; Tempera et al., 2012; Lawrence et al., 2015). Aerial photography as well as Light Detection and Ranging (LIDAR) are also employed to map physical aspects of the ocean floor. However, such mapping is only possible at shallower depths of up to $40 \mathrm{~m}$ (Zavalas et al., 2014). In order to supplement physical seascape information with biotic information of the benthos, several techniques can be utilized, such as dredging or trawling to collect samples (Ceia et al., 2013), whilst others have used video taken by remotely operated vehicles (ROVs) to characterize biota (Micallef et al., 2012). To survey smaller areas containing distinct biotic communities and their associated habitats [mesohabitats; 10-1000 m (van Rein et al., 2009, 2011)], divers typically characterize the benthos and its associated biota along transects or within quadrats by swimming or using diver propulsion vehicles, at times video recording the transect (Brown et al., 2004; Leujak and Ormond, 2007; Jokiel et al., 2015). Others have used towed-video or rotating cameras to characterize biological communities (Kenyon et al., 2006; Pelletier et al., 2012). Occasionally, mesoscale surveys include semi-quantitative methods of physical sampling through trawls and dredges (Lathrop et al., 2006). Both broad-scale and mesoscale assessments of biotic benthic communities can also be achieved through video surveying methods with ROVs (Tempera et al., 2012).
Over the past 30 years, rapid technological developments have produced increasingly inexpensive tools for conducting marine surveys, such as low-cost mini ROVs. Remotely operated vehicle employment has reduced some of the limitations of SCUBA surveys techniques, such as depth and survey time restrictions. Remotely operated vehicles have the advantage of extending dive time and depth whilst creating a permanent record, and facilitating resampling (Riegl et al., 2001; Lam et al., 2006). Marine surveying with an ROV has been done on both a mesoand broad scale (Stein et al., 1992; Pacunski et al., 2008; Campos et al., 2009; Cánovas-Molina et al., 2016), and the initial costs of purchasing and operating ROVs for smaller-scale projects are now feasible (Pacunski et al., 2008; Azis et al., 2012). Remotely operated vehicles are also versatile and fairly easy to operate (Leujak and Ormond, 2007; Pacunski et al., 2008). Remotely operated vehicles have now been used in numerous applications, such as characterizing rockfish habitat in California, British Columbia (BC), and Alaska, and surveying biotic communities in Washington and Oregon state (Richards, 1986; Stein et al., 1992; Pacunski et al., 2008).

Despite the usefulness of marine habitat assessments, most marine areas have never been surveyed, likely because of the high cost and the intensity of effort and analysis. Furthermore, for those that have been surveyed, many different classification schemes exist that characterize benthos, making comparisons of data or results difficult (Diaz et al., 2004; van Rein et al., 2011, 2009). One example of a consistent classification schema is the ShoreZone project ${ }^{1}$, developed in the 1980s and 1990s. It classifies the intertidal and nearshore habitat for all $37,619 \mathrm{~km}$ of shoreline across Oregon, Washington, British Columbia, and Alaska. ShoreZone provides biological and geological data of the intertidal and nearshore zones, enabling researchers to compare or complement their own data with the ShoreZone data on various scales. The overall methodology involves collecting low-tide imagery and completing a shoreline classification with descriptive biophysical attributes. Shorezone data only extends to the low intertidal, whilst it was used to help guide the surveys this project sought to extend comprehensive physical and ecological data to the subtidal using a mini ROV. Importantly, Shorezone has been used in British Columbia to inform marine spatial planning (MSP) in waters around Haida Gwaii (Shorezone, 2019a).

ROVs produce easily replicable, high quality data, and recent technological developments and crowdfunding projects have made acquiring and employing ROVs cost-effective. For example, OpenROV $^{2}$ was a Kickstarter project that offers a prebuilt ROV (called the Trident ROV), in addition to selling do-it-yourself kits to build your own ROV (Please note: OpenROV merged with the sea sensor developer Spoondrift in 2018 and is now known as Sofar Ocean Technologies, which continues to manufacture and sell the Trident). The prebuilt Trident ROV weighs $3.485 \mathrm{~kg}$ and is attached to a tether, which lets the pilot livestream the video onto a tablet or controller. The tether is available in lengths of 25 and $100 \mathrm{~m}$. Video can be recorded continuously

\footnotetext{
${ }^{1}$ www.ShoreZone.org

${ }^{2}$ www.openROV.org
} 
at a resolution of either 720 pixels or 1080 pixels, and the date and time are automatically recorded. The battery lasts approximately $3.5 \mathrm{~h}$. Software is continually updated and more advanced features such as flight stabilization or geographic tagging are expected to become available. The acquisition cost for mini ROVs is approximately $0.2-12 \%$ of the cost of other ROVs currently used for this kind of research. The availability of low-cost ROVs puts the technology within reach of projects with limited resources, but the technology is so new that the ease of operations and quality of the data will be tested and determined through this research.

The Songhees Nation, an Indigenous people whose traditional territory includes what is now known as Victoria, British Columbia, Canada, have been worried about the health of their traditional territory, which has seen significant urban development since European settlements were established in the 19 th century. As a result of this development and colonial policies from both the federal and provincial government, Songhees' members' ability to practice their Aboriginal and Douglas Treaty rights and culture has been severely diminished. Songhees has been actively working to protect and preserve the community's way of life and their Aboriginal and Douglas Treaty rights. Inspired by the Marine Plan Partnership's marine spatial plans for BC's North and Central Coast (MaPP) ${ }^{3}$ (Diggon et al., 2019) - a collaboration between seventeen First Nations from the Central and North Coast of British Columbia-the Songhees desired to produce their own spatial plans to support the ecological and cultural health of their traditional territory and to assert and establish exclusive Songhees stewardship.

To establish a baseline of the Songhees Indigenous seascape, we were interested in applying the new low-cost, mini ROVs for marine surveying of benthos and associated biota. In collaboration with the Songhees Nation, we seek to create this baseline of the Nation's culturally important seascape and species to allow the establishment of an ongoing monitoring system to gauge the seascape's ecological health for future generations.

${ }^{3}$ www.mappocean.org
Focusing on culturally important species allowed us to integrate a human dimension into this otherwise scientific undertaking of ecological monitoring (Moller et al., 2004, 2009). The purpose of our research was to (1) to create a present-day ecological baseline of the Songhees Indigenous seascape by documenting the physical substrate, benthic algal communities, and a variety of Songhees culturally important species, (2) test the applicability and capabilities of a low cost mini ROV to gather data to obtain a baseline in a case study seascape and (3) evaluate the ability of ROVs for informing marine use planning by the Songhees Nation in Canada.

\section{BACKGROUND}

This research was initiated by the Songhees Nation Lands Manager, who contacted researchers from the University of Victoria to assist with the process of marine conservation planning for a part of their territory. The study area for the Songhees marine conservation planning effort was focused on Discovery and Chatham Islands off South Vancouver Island in the so-called Salish Sea (Figure 1). The islands are collectively known as Tl'ches, or "one island," [Sellemah (J. Morris), pers. comm. to EB, June 2017] in the Lekwungen language, a Straits Salish dialect of the Coast Salish language (Suttles, 1974). The islands have longstanding importance for the Lekwungen peoples. Archeological evidence of occupation of Tl'ches dates likely back at least 3500 years but no systematic archeological research has been conducted to date (D. L. Mathews, pers. comm. to EB, October 2019). In more recent history, Tl'ches served as a refuge for several families during the small pox epidemic in the late 1800s (Suttles, 1974). Songhees people lived on Tl'ches until the 1950s, when the last inhabitants of the islands moved away because the only freshwater source dried up (C. Bryce, pers. comm. to EB, May 2017). Tl'ches features in an important creation story of the Lekwungen peoples as "The Origin of Salmon" (Jenness, 2016). It has been mentioned as a location for salmon harvesting camps for the various species of Pacific salmon

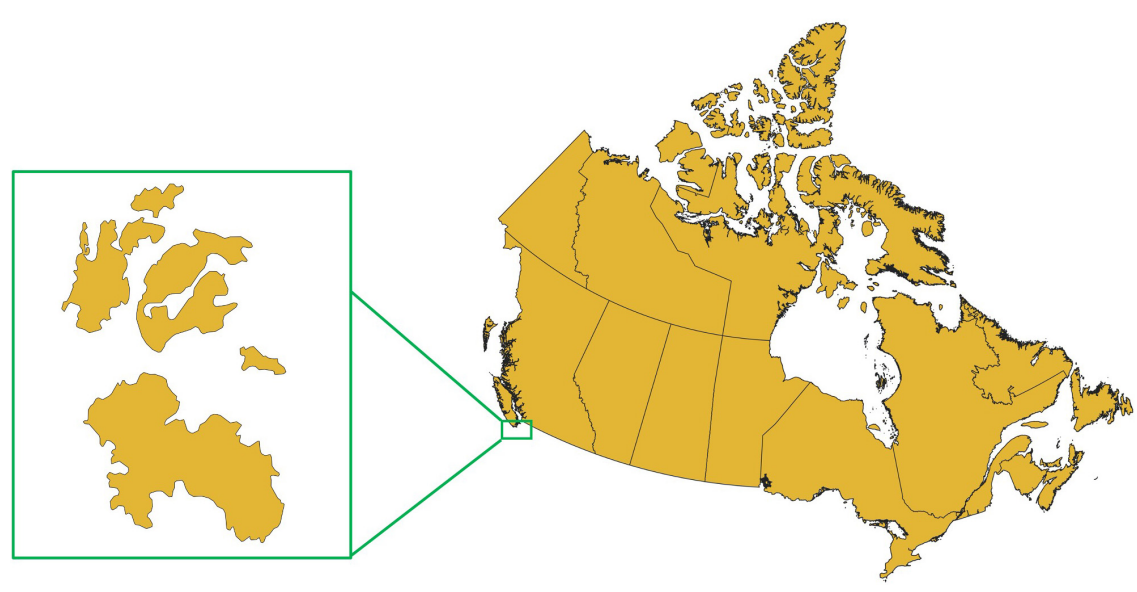

FIGURE 1 | Outline and location of Tl'ches on the British Columbia coast of Canada. 
(Onchorhynchus spp.) that pass Tl'ches on their migration route to spawning streams (C. Bryce, pers. comm. to EB, June 2017).

The jurisdiction over the sea- and landscape Tl'ches is complicated. The archipelago sits near a highly populated area on Southern Vancouver Island in BC, Canada. Cumulative impact assessment has shown the area as highly impacted (Ban et al., 2010). The shorezone and sea bottom is under provincial, and the water column (and hence all fisheries) is under federal jurisdiction. However, the Songhees affirm their stewardship rights over land and sea. There is also a Rockfish Conservation Area (federal designation) around the perimeter of the archipelago, and Tl'ches lies within the federally designated critical habitat for the Southern resident population of Orca whales (Orcinus orca). On land, most of Tl'ches is federally designated Songhees Nation Indian Reserve, and the Southern portion of Discovery Island is designated as the Discovery Island Marine Provincial Park. One small parcel on Discovery Island is privately owned.

Current non-indigenous uses of Tl'ches include commercial fisheries, recreational activities such as fishing and kayaking around the islands, and hiking by visitors off the BC Marine Park on South Discovery Island. The Songhees are very concerned about non-members trespassing on $\mathrm{Tl}^{\prime}$ ches reserve lands. Songhees uses include but are not limited to traditional harvesting of marine resources around the islands, Camas bulbs (Camassia quamash) on parts of Chatham Islands, as well as for educational trips for the Songhees Academic Youth League around Tl'ches. The Songhees Nation has become increasingly concerned with the effects of irresponsible usage of the islands by recreational users, which has been going on for at least four decades. Former Songhees Chief John Albany (radio interview, September 20, 1973) stated: "Chatham Island and the Southern part of Discovery Islands (are) closed to outsiders as some visitors abused the privilege by being careless".

Tl'ches is an ecologically and culturally rich archipelago. In addition, its location affects the islands ecological productivity. For example, the entire tidal volume of the Strait of Georgia drains by Tl'ches twice a day. In addition, the wave exposure on the Southeast-facing coast is amongst the highest in the entire Salish Sea with a strong energy gradient from exposed to protected lagoon shores. The seascape environment ranges from high exposure rocky channels and platforms, to sand and gravel beaches, to intertidal mudflats (Shorezone, 2019b). There are exposed and submerged rocks scattered between the islands, which provide dangers to boaters unfamiliar with the waters. Tl'ches contains a number of culturally significant sites for the Songhees people. These include both large winter villages and summer resources sites, as well as coastal root gardens and clam beds created and/or enhanced by previous Lekwungen occupants of Tl'ches (D. L. Mathews, pers. comm. to EB, June 2017). Coastal root gardens were used to cultivate traditionally important foods such as Pacific silverweed (Podospora anserina) and springbank clover (Trifolium wormskioldii) (Deur, 2005).

Other marine species of importance include kelp forests, which surround parts of Tl'ches, and eelgrass (Zostera marina) found mostly between the islands of the archipelago. The most conspicuous culturally important species is the Pacific harbor seal (Phoca vitulina), which basks on rocks all around Tl'ches. Previous dive surveys in the waters off Tl'ches have noted the occurrence of 39 marine vertebrate and 42 invertebrate species (Reef Environmental Education Foundation, 2017a,b,c). Whilst there is some data on the presence of marine species, there has been no comprehensive, systematic mapping of the seafloor, and no ecological baseline inventory of Songhees culturally important species has been conducted to date.

\section{MATERIALS AND METHODS}

To meet our objectives, our research followed several steps: first, working with Songhees members, we identified culturally important species for the Songhees Nation to be tracked during underwater surveys (Buscher et al., in review). Second, we conducted trial transects to train the research team in operating the ROV, and to test the anticipated methods. Third, we conducted underwater surveys to capture video footage of the seafloor and associated biota. Finally, we analyzed the footage to characterize the benthos, and identify and count the culturally important species. We selected the Trident ROV by OpenROVwhich we received as beta-testers - as the best current technology and value for money.

We identified the culturally important species through two sources: by reviewing the ethnographic literature concerning Lekwungen marine ethnoecology, and through interviews with Songhees community members (UVic ethics \# 17-445). We used the dissertation of an ethnologist (Suttles, 1974) to develop the initial list of known harvested marine invertebrate and vertebrate species by the Songhees Nation peoples. The materials we reviewed do not constitute a complete review of the literature on the Lekwungen peoples. For instance, archeological work of additional culturally important species to the Lekwungen peoples has been compiled (D. L Mathews, pers. comm. to EB, February 2019). We (led by Songhees team members and co-authors Kathleen Bryce and Darlene Joseph) then conducted semi-structured interviews (Huntington, 2000) with Songhees members about the importance of $\mathrm{Tl}^{\prime}$ ches, and added additional species mentioned in interviews with Songhees members to those that emerged from the literature review.

For the underwater transect aspect of the project, we used the random points tool in ArcMap 10.6. (ESRI, 2011) to generate stratified random starting points. We selected ROV transects so that our surveys included all known substrate types as designated by the ShoreZone project ${ }^{1}$ by stratifying by the low water mark habitat classifications. The random points tool created 59 transect points. We supplemented the original transect points with three areas of high disturbance or previous heavy use, resulting in 62 transect locations in total. Transect points were evenly divided amongst the eight shore type classifications assessed by the ShoreZone project. Our team of 3-4 people conducted transects during the daytime at slack tide between March and May 2018 from a $22 \mathrm{ft}$ zodiac that was usually anchored for the duration of the surveys. We started transects at the random points, or the closest safe location. We were unable to complete some transects $(n=11)$ due to the inability of the ROV to withstand the high 
current flows in certain areas even at slack tide, and due to other physical constraints (e.g., bottom too shallow). Some starting points $(n=12)$ were so close together that we surveyed them in one transect $(n=6)$. In total, we surveyed 45 transect locations.

Transects ran perpendicular to shore using the integrated compass in the ROV for navigation (Figure 2). Video recording started when the ROV entered the water, and stopped when we reached the end of the tether. Whilst the ROV tether was $100 \mathrm{~m}$, due to current movements and depth change we estimate that total transect length was approximately $80 \mathrm{~m}$.

We used the OpenROV application and software (Version 2.14) on a Samsung Galaxy Tab S2 tablet to operate the ROV and record videos (OpenROV, 2017). We recorded the coordinates of the start of each transect and other observations such as weather conditions, sea conditions, estimated maximum depth and notable sightings. We were unable to document the GPS location for each transect end point. Depth was categorized into three strata: shallow $(0-10 \mathrm{~m})$, medium $(11-20 \mathrm{~m})$ and deep $(>20 \mathrm{~m})$. The classification of depth strata yielded 29 transects in shallow, 13 transects in medium and three transects in deeper waters.

We analyzed videos to characterize the substrate types, or algal cover if benthos was overgrown. Following the benthos classification methodology developed by Stein et al. (1992), we categorized dominant substrates by classifying the stills into

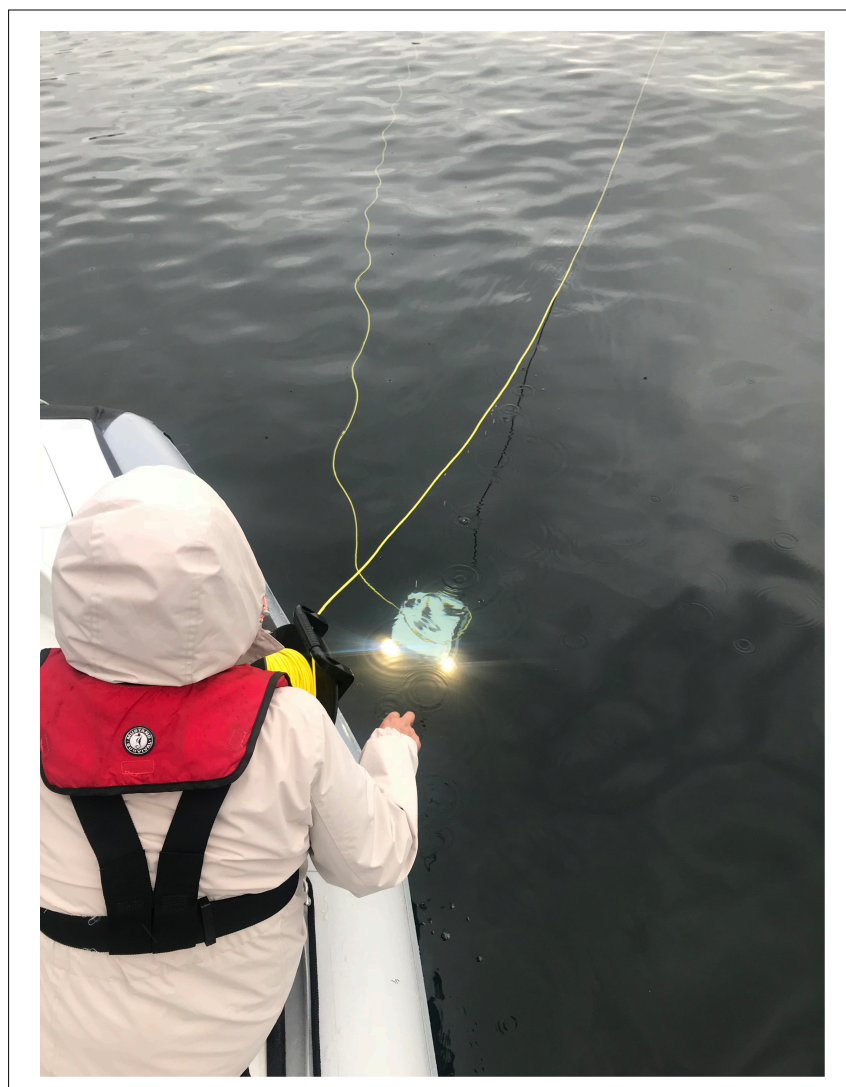

FIGURE 2 | Image of the Trident as it returns to the survey team after a transect. primary and secondary benthos. We focused on the three possible categories in line with the ShoreZone low water mark habitat classification for Tl'ches-sand, gravel and rock. As in Stein et al. (1992), we ascribed the primary benthos type when substrate cover exceeded $50 \%$ of the area viewed, and secondary benthos type when it covered more than $20 \%$ of the area viewed. Any transect still that exceeded $80 \%$ of one single benthos type did not have a secondary benthos category ascribed to it.

Studies have shown that still photographs yield the same results as video analysis, but with considerably less analysis time for benthic surveying (Cabaitan et al., 2007; Jokiel et al., 2015; Kenyon et al., 2006; Hill and Wilkinson, 2004). Therefore, we employed the screengrab function of the VLC media player Version 3.0.2 (VideoLAN, 2018) to generate stills. Generating stills did not cause any discernable resolution loss. We defined the beginning of each transect as when the ROV showed the substrate and was moving parallel to the benthos (i.e., no longer descending). We slowed down transect videos to about $0.50 \times$ speed to determine the starting point for each transect. We then watched the individual transects multiple times (approximately three) to determine the number of seconds of survey time that needed to pass to show a new field of view (so that the benthos and algal community was different for each still), and used that interval for subsequent stills for that transect yielding on average approximately 60 stills per transect. If it was impossible to maintain one interval per given transect, we adjusted the interval to account for velocity change of the ROV due to currents.

We quantified percentage cover and composition of the benthos and algae, overlaying a grid onto the substrate of each still (sensu Kenyon et al., 2006). When we were unable to either identify the benthos type due to the instability of the ROV (resulting in images that were too pixelated to identify or did not show any benthos), we assigned a NA (non-applicable) to that screengrab. Many screengrabs had just one category $(>80 \%$ of the transect as a single category), and thus the proportion of secondary benthos composition was low. We identified algae using the Biodiversity of the Central Coast guide for seagrass and macroalgae (Biodiversity of the Central Coast, 2017). We analyzed each still using the freeware ImageJ (Rasband, 2018). When algal coverage equaled $100 \%$ of the field of view in stills, we inferred primary substrate type (mostly rock) given the preferred substrate for a given algal species.

To document the incidence and occurrence of the culturally important macrofauna, we viewed the continuous video to identify the culturally important species down to genus and species wherever possible. In contrast to using stills for the benthos classification, we opted to watch continuous video so as to ensure that all occurring species were counted. We counted every individual of a given culturally important species whenever possible. Due to the low stability of the ROV in high flow environments [a common problem for mini to mid-sized ROVs (Pacunski et al., 2008)], and high turbidity or software transmission problems impeding video resolution, we recorded the duration of the transect during which highly abundant species ( $>10$ per still) occurred instead of counting them. We did this to avoid double counting, and to avoid misidentification by failing to distinguish red and purple urchin (Mesocentrotus sp. and 
Strongylocentrotus sp.) due to low light levels. Duration was also recorded for the rock scallop (Crassadoma gigantea) in particular.

We ran a non-metric multi-dimensional scaling ordination with the vegan package (version 2.0-10) in $\mathrm{R}$ version 2.15.1 ( $\mathrm{R}$ Studio Team, 2015) to see whether an inference could be made on co-occurring culturally important species, which in turn could highlight important areas for protection. So as not to skew the ordination, we excluded any observation with a count of one. We also ran generalized linear models in $R$ to test for which predictors (percentage of algal cover; percentage of primary benthos type cover; percentage of secondary benthos type cover; depth) best explained Songhees culturally important species richness. The model with the least AIC score was determined to be the option that best explained the data (Burnham et al., 2011).

\section{RESULTS}

Our literature review of the Songhees Nation culturally important marine species identified 18 invertebrate species and 6 vertebrate genera (Table 1). Interviews by and with Songhees Nation members mentioned most of these species including two new ones. They also pointed to other traditionally hunted marine species such as waterfowl and seabirds. While these were also

TABLE 1 | List of Songhees marine culturally important species compiled from Suttles $(1974)\left({ }^{(}\right)$and interviews with Songhees members $\left({ }^{\star *}\right)$.

\begin{tabular}{|c|c|}
\hline Common name & Scientific name \\
\hline Red urchin* & S. franciscanus \\
\hline Green urchin* & S. droebachiensis \\
\hline Purple urchin* & S. purpuratus \\
\hline Keyhole limpets ${ }^{\star *}$ & Megathura sp. \\
\hline Rockfish** & Sebastes spp. \\
\hline Pacific herring* & C. pallasii \\
\hline Lingcod* & O. longates \\
\hline Pacific Salmon* & Onchorhynchus spp. \\
\hline Giant Pacific Octopus* & E. dofleini \\
\hline Northern Abalone* & H. kamtschatkana \\
\hline Harbor Seal* & P. vitulina \\
\hline Pacific halibut ${ }^{\star}$ & H. stenolepis \\
\hline Giant California Sea cucumber* & A. californicus \\
\hline Gumboot chiton* & C. stelleri \\
\hline Native oyster ${ }^{*}$ & O. lurida \\
\hline Blue mussel ${ }^{*}$ & M. edulis \\
\hline Pacific cockle* & C. corbis \\
\hline Butter clam* & S. gigantea \\
\hline Pacific littleneck clam & P. staminea \\
\hline Bentnose clam* & M. nasuta \\
\hline White-sand macoma* & M. secta \\
\hline Horse clam/Pacific gaper* & T. nuttallii \\
\hline Barnacle* $^{*}$ & Balanus sp. \\
\hline Dungeness crab* & M. magister \\
\hline Rock scallop & C. gigantea \\
\hline
\end{tabular}

The bolded species are predominantly subtidal, whereas the others are considered intertidal. The species with a shaded background represent those found present in our transects $(n=14)$ and observations $(n=1)$. mentioned by Suttles (1974), we did not focus on them in our surveys because they are not considered subtidal. Our finalized list contained 24 subtidal culturally important marine species (Table 1).

Overall, we found 14 culturally important species or genera to be present. We found nine culturally important species in our most species-rich transect. Rock was the most commonly occurring substrate in the form of boulders, flat rock, and rocky ridges, i.e. continuous rocky benthos (Figure 3A).

Algal cover (Figure 3C) was present in every but one transect, ranging from 1 to $100 \%$ (average 59\%). With the exception of one shallow transect, the deep transects $(n=3)$ showed the least average algal cover (1.33\%). Algal cover encompassed all types of algae (red, brown, and green), and we were able to confirm the presence of at least 28 species of algae (Table 2 ).

We recorded 14 of the 24 listed culturally important species. Apart from rockfish (Sebastes spp.), 13 species were invertebrates. While not seen in transects, we observed harbor seals from the surface on several occasions. The generalized linear models revealed that the best model $(\mathrm{AIC}=179.18)$ for culturally important species richness included two significant predictors, shallow depth $(0-10 \mathrm{~m})(p<0.0005)$ and medium depth $(11-20 \mathrm{~m})(p<0.002)$. The ordination plot revealed certain species to occur more closely together (e.g., Strongylocentrotus spp. and C. gigantea) but overall did not reveal any other trends (Figure 4).

\section{DISCUSSION}

Ours was the first study that we know of that used the new mini ROV Trident by OpenROV to survey a marine environment. In partnership with the Songhees Nation, we found that the Trident was a useful tool for our purposes, although it had some limitations. We use the discussion to reflect on the objectives of our study: (1) to create an ecological baseline of the Songhees Indigenous seascape by documenting the physical substrate, benthic algal communities, and a variety of Songhees culturally important species, (2) test the applicability and capabilities of a low cost mini ROV to gather data to obtain a baseline in a case study seascape, and (3) evaluate the ability of ROVs for informing marine use planning by the Songhees Nation in Canada.

\section{Ecological Baseline Observations}

Overall, the Trident worked well to generate baseline observation, although it also had some limitations. Typically, we expect a higher diversity of benthic invertebrate species in marine high flow environments (Palardy and Witman, 2011, 2014). However, limitations of the Trident-inability to operate in high-flow environments and kelp beds - means that we were unable to survey some areas near Tl'ches, potentially missing culturally important species hotspots and biodiverse areas. Research using other technologies also showed similar challenges, namely difficulty maneuvering ROVs in high rugosity and high flow environments (Pacunski et al., 2008; Benoist et al., 2019). Similar to our methodology, research was conducted around slack tides and other researchers tried to work with surface 
A

\begin{tabular}{|c|c|c|}
\hline Gravel (\%) & Rock (\%) & Sand (\%) \\
\hline 9 & 18 & 71 \\
\hline 0 & 36 & 64 \\
\hline 29 & 66 & 0 \\
\hline 0 & 25 & 69 \\
\hline 8 & 58 & 25 \\
\hline 16 & 41 & 32 \\
\hline 0 & 30 & 67 \\
\hline 76 & 7 & 0 \\
\hline 0 & 88 & 2 \\
\hline 7 & 81 & 10 \\
\hline 79 & 21 & 0 \\
\hline 0 & 100 & 0 \\
\hline 0 & 100 & 0 \\
\hline 0 & 63 & 38 \\
\hline 45 & 55 & 0 \\
\hline 0 & 0 & 97 \\
\hline 92 & 0 & 0 \\
\hline 25 & 69 & 0 \\
\hline 38 & 25 & 30 \\
\hline 2 & 95 & 0 \\
\hline 3 & 97 & 0 \\
\hline 35 & 55 & 10 \\
\hline 74 & 7 & 17 \\
\hline 6 & 12 & 78 \\
\hline 0 & 61 & 0 \\
\hline 4 & 87 & 4 \\
\hline 45 & 52 & 0 \\
\hline 0 & 17 & 65 \\
\hline 8 & 85 & 0 \\
\hline 11 & 51 & 26 \\
\hline 25 & 45 & 21 \\
\hline 0 & 63 & 15 \\
\hline 34 & 34 & 32 \\
\hline 21 & 25 & 0 \\
\hline 20 & 20 & 43 \\
\hline 3 & 0 & 97 \\
\hline 32 & 36 & 8 \\
\hline 14 & 12 & 71 \\
\hline 0 & 40 & 58 \\
\hline 56 & 35 & 0 \\
\hline 4 & 62 & 30 \\
\hline 0 & 0 & 100 \\
\hline 0 & 73 & 13 \\
\hline
\end{tabular}

B

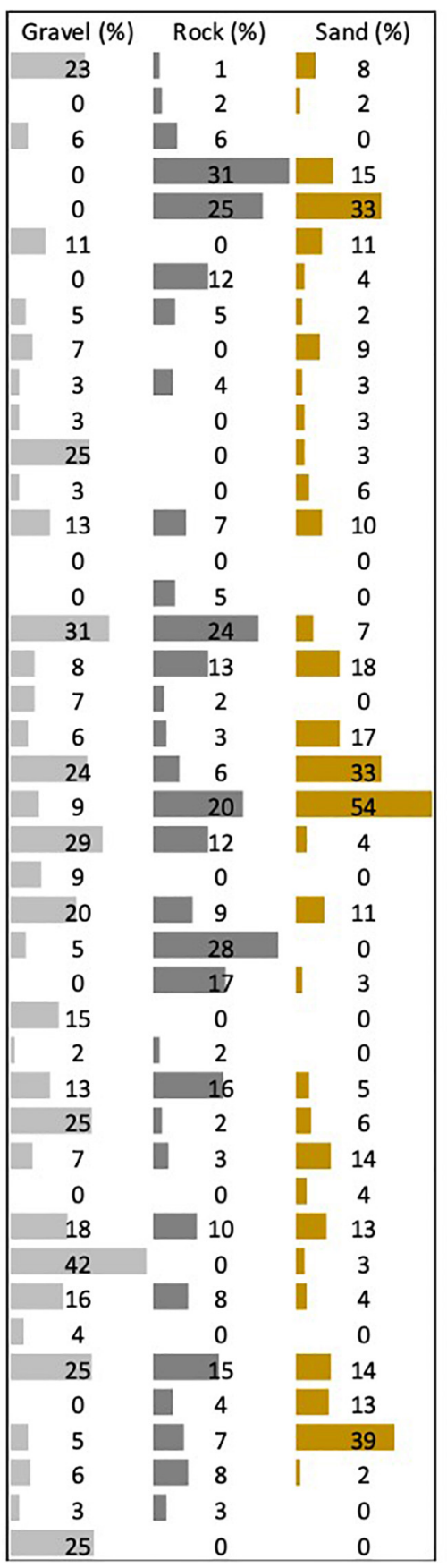

C

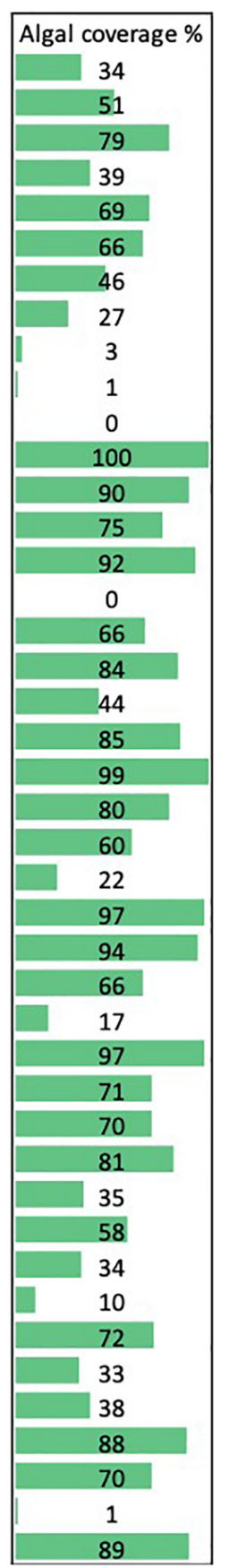

FIGURE 3 | Percentage average of (A) primary benthos type composition by transect. Percentage average of (B) secondary benthos type composition by transect. (C) Percentage of algal cover.

currents (Pacunski et al., 2008), whereas the Trident was at times completely overpowered by stronger ( $\sim 2.5$ knots) surface currents. In our analyses of the individual transects we attempted to quantify the present species to our best abilities; however, we were unable to produce an error estimate of species count.

When transects have been deployed perpendicular to shore, descending into sublittoral, they have successfully recorded changes in community assemblages with depth at a biotope level
(Parsons et al., 2004; Moore et al., 2006; Shears, 2007). Our survey could have missed culturally important biota because of kelp dense areas (limiting ROV manoeuvrability) and over substrata with dense algal cover (obscuring understory biota) (Leonard and Clark, 1993; Pacunski et al., 2008). Kelp forests as well as eelgrass are highly productive habitats for many species, acting as nurseries as well as refuge for many fish and invertebrate species (Levinton, 2013). Finally, whilst this was the first survey to 
TABLE 2 | Documented macroalgae around Tl'ches.

\begin{tabular}{|c|c|}
\hline Common name & Scientific name \\
\hline Sieve kelp & Agarum sp. \\
\hline Ribbon kelp & Alaria marginata \\
\hline Red sea fan & Callophyllis sp. \\
\hline Coralline algae & Corallinales \\
\hline Graceful coral seaweed & Corralina vancouveriensis \\
\hline Five-ribbed kelp & Costaria costata \\
\hline Three-ribbed kelp & Cymathaere triplicata \\
\hline Acid kelp & Desmarestia spp. \\
\hline Feather boa & Egregia menziesii \\
\hline Rockweed & Fucus sp. \\
\hline California limu & Gracilaria pacifica \\
\hline Sea spaghetti & Gracilaria andersonii \\
\hline Southern stiff-stiped kelp & Laminaria spp. \\
\hline Giant perennial kelp & Macrocystis spp. \\
\hline Splendid iridescent seaweed & Mazzaella spp. \\
\hline Sea fern & Neoptilota spp. \\
\hline Bull kelp & Nereocystis luetkeana \\
\hline Frilly red ribbon & Palmaria sp. \\
\hline Broad-ribbed kelp & Pleurophycus gardneri \\
\hline Bleachweed & Prionitis sp. \\
\hline Woody-stemmed kelp & Pterygophora californica \\
\hline Sea felt & Pylaiella littoralis \\
\hline Red islet silk & Sparlingia pertusa \\
\hline Sea cabbage & Saccharina sp. \\
\hline Japanese wireweed & Sargassum muticum \\
\hline Turkish towel & Chondracanthus exasperatus \\
\hline Dark sea lettuce & Ulvaria sp. \\
\hline Eelgrass & Zostera marina \\
\hline
\end{tabular}

establish an ecological baseline around $T l$ 'ches, future monitoring should investigate other technologies (e.g., scuba diving, drop camera) to survey high current environments, since a diverse array of monitoring methods can better address the complexity of ecosystems (Hilty and Merenlender, 2000).

While our surveys allowed us to ascertain a baseline, by themselves they do not provide enough information to assess the health of the system. There are many ways of assessing degraded versus healthy ecosystems through environmental monitoring (Diaz et al., 2004; Salas et al., 2006). For initial baseline data, such as species richness, to become meaningful for a monitoring program, it is necessary to consider the species' general life history strategies and tolerances to changes in environmental quality (Carballo and Naranjo, 2002). For example, kelp forests in temperate regions are predicted to shift ranges with climatic changes, possibly shifting and altering whole habitats (Marzinelli et al., 2015). Similar potential threats ought to be assessed and life histories and environmental tolerances ought to be considered by the Songhees Nation when developing a monitoring system to evaluate ecological health of the Tl'ches seascape. The most notably degraded transects we conducted (with recommendation from our skipper) were typically associated with low biodiversity and stunted growth or complete absence of macroalgae or other biota. Indeed, macroalgae has been shown to serve as an indicator for environmental quality in stressed versus healthy environments, with highly stressed environments showing little to no algal cover (Juanes et al., 2008). We suspect toxic paint and other heavy metals might contaminate these areas as these spots used to serve as a log boom and/or an area were boat paint used to be scraped off (I. Cesarec, pers. comm. to EB, August 2017). Confirming these areas as highly stressed facilitates Songhees to concentrate restoration efforts in the future.

The ordination plot did not reveal any species that closely co-occurred other than green urchin (Strongylocentrotus droebachiensis) and rock scallop (C. gigantea), which might be explained due to the fact that rock scallop was only recorded at a very small number of transects $(n=4)$ and only in conjunction with echinoids, thus skewing the ordination. While we only found depth to be a significant predictor of number of species, a study conducting similar research in the Celtic Sea found that hard substrates (rock, boulders, gravel) had the highest species diversity and biomass (Benoist et al., 2019). Another result of the same study showed that coarse habitats (gravel and sand) exhibited the lowest species diversity and biomass (Benoist et al., 2019). Our surveys could not confirm nor reject these substrate types as predictors of species diversity statistically, however, qualitatively these species diversity-substrate associations seemed to hold true. In addition, we did not focus on biotope monitoring [surveying the whole species assemblage and benthos (van Rein et al., 2009)] so these associations could have simply been missed.

Overall, the fact that there is no significant association between species highlights the importance of protecting the whole Indigenous seascape Tl'ches. Our models showed the only significant predictors of culturally important species richness as shallow and medium depth. Overall, the bathymetry around Tl'ches is mostly shallow to medium depth. These are also the areas that are most accessible for harvesting of culturally important species to the Songhees people in the past and the present day.

\section{The ROV and Its Advantages/Drawbacks/Applicability for Marine Surveying and Monitoring}

For communities or organizations that are short of financial or personnel capacity, the Trident offers a comparatively cheap, safe and reliable alternative to conducting dive or towed diver surveys. We were beta testers for OpenROV, allowing us to provide feedback about technological issues such as software glitches. The Trident allows for nearshore and offshore surveying with transect lengths of up to $100 \mathrm{~m}$, and possible dive depths of up to $100 \mathrm{~m}$. Our surveys took place in nearshore environments with depths of 0-30 m, where SCUBA or towed dive surveys are commonly utilized (Kenyon et al., 2006; Leujak and Ormond, 2007). Additionally, depending on survey depth, divers are constrained to three dives per day, whereas Trident ROV surveys times can last up to $3 \mathrm{~h}$ without interruption. Depending on the survey technique used, the Trident allows for video recording and possible resampling of the video footage in the future. In addition, although not applicable in our study, surveying in highly polluted environments such as oil spills becomes a possibility with ROVs 


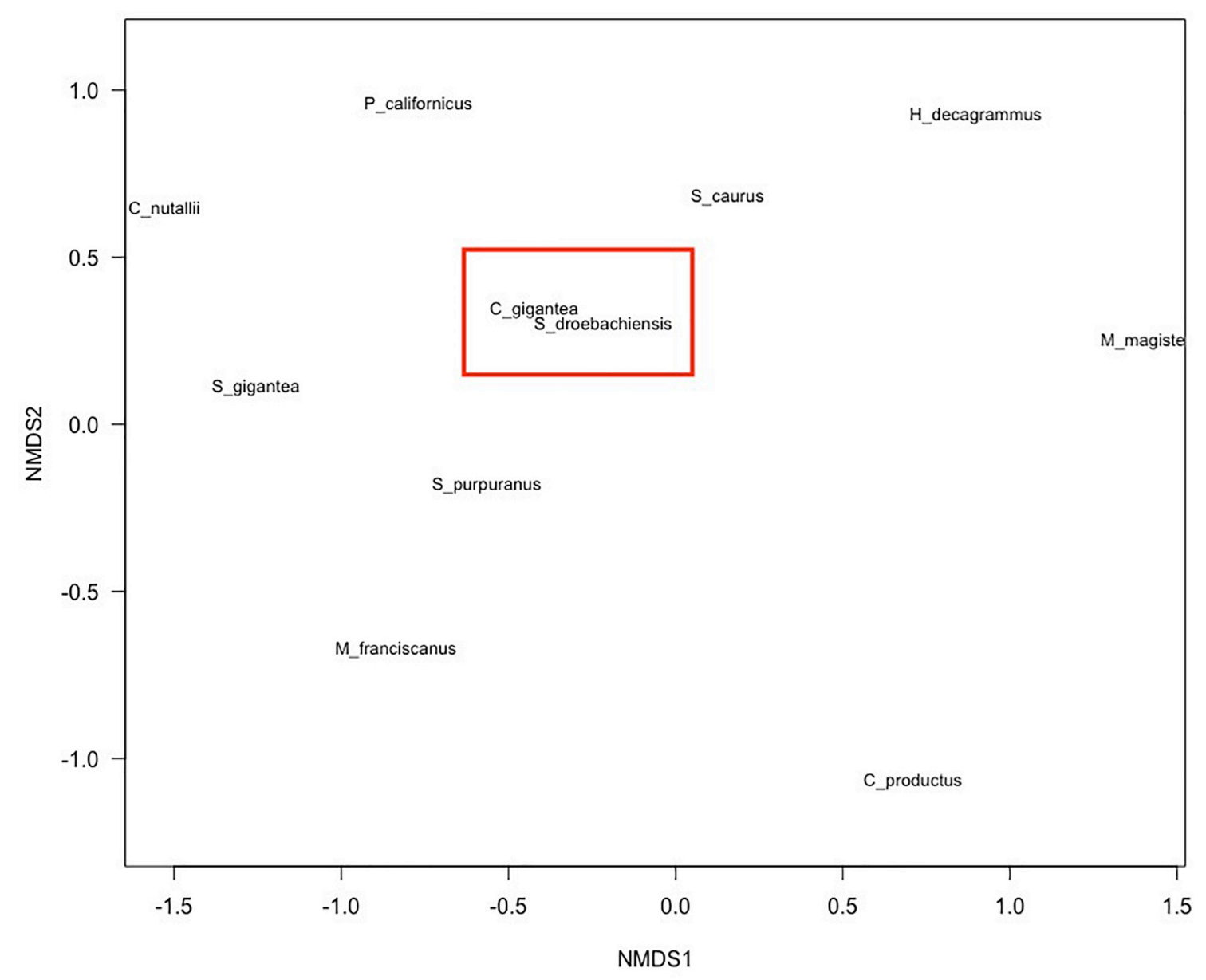

FIGURE 4 | Non-metric multi-dimensional scaling ordination showing the relationship of species co-occurrence. Two Songhees culturally important species, namely, S. droebachiensis and C. gigantea appear to be co-dependent (highlighted by the red box) Stress = 0.25.

(Hughes et al., 2010). Overall, utilizing a mini, low-cost ROV such as the Trident can (1) extend dive time and depth, (2) reduce personnel, (3) preparation and overall survey time, and (4) be safe and cheaper. As beta testers, we found that the Trident was a cost-effective means of gathering a variety of ecological information.

Learning how to pilot the Trident with a tablet or the controller offered through OpenROV was intuitive. Perfecting to pilot the Trident does, however, require a steep learning curve. The controls are sensitive, where the ROV responds immediately to minor adjustments in direction and/or speed. The Trident dives well and has integrated lights, which were not tested in the context of this research as we did not operate at night. The battery life is around three hours, as advertised. The resolution of the camera and the video output is good, especially at $1080 \mathrm{p}$, which had been temporarily disabled by the developers due to software instability but was enabled again when requested. The transect videos downloaded quite easily. The software, despite some glitches (such as not being able to install the updates without aid of the OpenROV team) was more or less stable and functioning especially with continual updates.

The Trident overall was a very versatile and capable field assistant and allowed for the identification of many of our culturally important target species, but its ability to resolve smaller macrofauna $(<5 \mathrm{~cm})$ or buried organisms was turbidity and flow-dependent, as well as ROV velocity dependent, as is the case for other surveys (Cabaitan et al., 2007). Strict species counts might not work in the marine environment due to a typically high flow and turbidity environment; they might however be better suited in low flow lentic environments. Tropical environments such as coral reefs, where visibility tends to be higher than in temperate regions yearround, could also prove to be better suited for ecological surveying using the Trident. Another factor could also be that many ROV cameras are unable to resolve small species due limitations of camera resolution, which is typically set at 1080p (Jokiel et al., 2015; Torquato et al., 2017). Recent work with autonomous underwater vehicles has shown that higher resolution cameras can resolve macrofauna to about $1 \mathrm{~cm}$ 
(Benoist et al., 2019) thus including a higher resolution camera in a newer Trident iteration could improve species identification.

Similarly, the ROV is well built; however minor denting of the outer casing occurred during piloting but did not affect functioning. We also came across an issue of corrosion of the motors within the first two to four weeks (also reported by other beta users) despite a freshwater soak each time post usage. OpenROV resolved this swiftly by replacing this generation of motors.

Several improvements in the Trident could increase usability for surveying. The current version of the software does not gather data on variables such as temperature, water depth, geographic location and ROV orientation. Information on these variables would be highly advantageous for replicating transects and more information for continued monitoring. Another suggestion to improve the Trident would be to integrate lasers to estimate transect width or species size. Many higher end ROVs or other systems have this capability (Stein et al., 1992; Tissot, 2007; Yoklavich et al., 2007).

\section{Usefulness for the Songhees Nation Marine Conservation Planning}

The information we collected with the Trident enabled us to establish a baseline of culturally important species occurring around Tl'ches, which informed the Songhees Nation Marine Use Plan (Buscher et al., in review) and assist the Nation to negotiate protection for this ecocultural seascape. We did this by establishing the presence of at least 14 of 24 culturally important species and extended the shorezone shore-type information to the subtidal as well as established a systematic and comprehensive benthos classification. High resolution data is a precursor to many conservation planning initiatives (Margules and Pressey, 2000; Pressey and Bottrill, 2009; Mills et al., 2010). Protecting Tl'ches for Songhees cultural, social and ceremonial use only will potentially aid in revitalizing aspects of their culture for generations to come.

We documented the substrate and algal cover composition of the benthos, which could serve as one reference point for the Songhees Nation established monitoring system. Our models identified the shallow and medium depth strata as the only significant predictors explaining culturally important species richness, which shows the importance of protecting the whole archipelago around to a depth of at least $20 \mathrm{~m}$ to protect culturally important species. This was in accordance with the general vision and goals that the Songhees Nation established during interviews and consultations with Songhees community members (Buscher et al., in review). Tl'ches continues to be a culturally important place for Songhees peoples and many interviewees mentioned the need to have the islands protected for Songhees use for current and future generations. Indeed, in our interviews with Songhees members mentioned other culturally important species that went beyond the scope of this research, such as seabirds or waterfowl. This highlights another limitation of our research, which is our focus on subtidal species. Therefore, other culturally important species should be included in a monitoring program for Tl'ches to more accurately assess the whole ecocultural system that is Tl'ches.

\section{DATA AVAILABILITY STATEMENT}

All datasets presented in this study are included in the article/Supplementary Material.

\section{ETHICS STATEMENT}

The studies involving human participants were reviewed and approved by the University of Victoria Human Research Ethics Board (\#17-445). The patients/participants provided written informed consent to participate in this study.

\section{AUTHOR CONTRIBUTIONS}

EB: writing - original draft preparation, conceptualization, methodology, writing - reviewing and editing. DM: conceptualization, methodology, supervision, writing reviewing and editing. CB: conceptualization, supervision, writing - reviewing and editing. KB and DJ: writing - reviewing and editing. NB: conceptualization, methodology, supervision, writing - reviewing and editing. All authors contributed to the article and approved the submitted version.

\section{FUNDING}

This research was financially supported by NB. NB acknowledges support from the Social Sciences and Humanities Research Council SSHRC (grant \#435-2013-0059) and the Natural Sciences and Engineering Research Council of Canada NSERC (grant \#435785).

\section{ACKNOWLEDGMENTS}

EB would like to thank the Songhees Nation for allowing her the opportunity to work together on this project. EB would further like to extend her deep gratitude to $\mathrm{NB}$ and $\mathrm{DM}$ for all their support throughout this project and beyond. NB acknowledges the support from the Social Sciences and Humanities Research Council and the Natural Sciences and Engineering Research Council.

\section{SUPPLEMENTARY MATERIAL}

The Supplementary Material for this article can be found online at: https://www.frontiersin.org/articles/10.3389/fmars. 2020.00669/full\#supplementary-material 


\section{REFERENCES}

Azis, F. A., Aras, M. S. M., Rashid, M. Z. A., Othman, M. N., and Abdullah, S. S. (2012). Problem identification for underwater remotely operated vehicle (ROV): a case study. Proc. Eng. 41, 554-560. doi: 10.1016/j.proeng.2012.07.211

Ban, N. C., Alidina, H. M., and Ardron, J. A. (2010). Cumulative impact mapping: advances, relevance and limitations to marine management and conservation, using Canada's Pacific waters as a case study. Mar. Policy 34, 876-886. doi: 10.1016/j.marpol.2010.01.010

Benoist, N. M. A., Morris, K. J., Bett, B. J., Durden, J. M., Huvenne, V. A. I., Le Bas, T. P., et al. (2019). Monitoring mosaic biotopes in a marine conservation zone by autonomous underwater vehicle. Conserv. Biol. 33, 1174-1186. doi: $10.1111 /$ cobi.13312

Berkes, F. (2015). Coasts for People: Interdisciplinary Approaches to Coastal and Marine Resource Management. Abingdon: Routledge. doi: 10.4324/ 9781315771038

Biodiversity of the Central Coast (2017). Seaweeds (Algae) and Seagrass. Available online at: https://www.centralcoastbiodiversity.org/seaweeds-algaeand-seagrasses.html (accessed August 10, 2018).

Brown, E. K., Cox, E., Jokiel, P. L., Paul, L., Rodgers, S. K., Smith, W. R., et al. (2004). Development of benthic sampling methods for the coral reef assessment and monitoring program (CRAMP) in Hawai'i. Pacific Sci. 58, 145-158. doi: $10.1353 /$ psc.2004.0013

Burnham, K. P., Anderson, D. R., and Huyvaert, K. P. (2011). AIC model selection and multimodel inference in behavioral ecology: some background, observations, and comparisons. Behav. Ecol. Sociobiol. 65, 23-35. doi: 10.1007/ s00265-010-1029-6

Cabaitan, P. C., Licuanan, W. Y., and Gomez, E. D. (2007). Comparison between videographic and photographic methods in assessing coral reef benthic communities. Sci. Diliman 19, 7-13.

Campos, L., Moura, R., Veríssimo, I., Curbelo-Fernandez, M., Cavalcanti, G., and Brasil, A. (2009). "ROV imaging of deep-sea echinoderms from the Brazilian continental margin, Southwest Atlantic," in Proceedings of the 12th International Echinoderm Echinoderms, (Durham: CRC Press), 147-152. doi: 10.1201/9780203869543-c22

Cánovas-Molina, A., Montefalcone, M., Bavestrello, G., Cau, A., Bianchi, C. N., Morri, C., et al. (2016). A new ecological index for the status of mesophotic megabenthic assemblages in the mediterranean based on ROV photography and video footage. Continent. Shelf Res. 121, 13-20. doi: 10.1016/j.csr.2016. 01.008

Carballo, J. L., and Naranjo, S. (2002). Environmental assessment of a large industrial marine complex based on a community of benthic filter-feeders. Mar. Pollut. Bull. 44, 605-610. doi: 10.1016/S0025-326X(01)00295-8

Ceia, F. R., Patrício, J., Franco, J., Pinto, R., Fernández-Boo, S., Losi, V., et al. (2013). Assessment of estuarine macrobenthic assemblages and ecological quality status at a dredging site in a southern Europe estuary. Ocean Coast. Manage. 72, 80-92. doi: 10.1016/j.ocecoaman.2011.07.009

Cheng, L., Abraham, J., Hausfather, Z., and Trenberth, K. E. (2019). How fast are the oceans warming? Science 363, 128-129. doi: 10.1126/science.aav7619

Deur, D. (2005). “Tending the garden, making the soil: Northwest Coast Estuarine gardens as engineered environments," in Keeping it Living: Traditions of Plant Use and Cultivation on the Northwest Coast of North America, eds D. Deur and N. J. Turner (Seattle, WA: University of Washington Press), 296-327.

Diaz, R. J., Solan, M., and Valente, R. M. (2004). A review of approaches for classifying benthic habitats and evaluating habitat quality. J. Environ. Manage. 73, 165-181. doi: 10.1016/j.jenvman.2004.06.004

Diggon, S., Butler, C., Heidt, A., Bones, J. A., Jones, R., and Outhet, C. (2019). The marine plan partnership: indigenous community-based marine spatial planning. Mar. Policy 103510. doi: 10.1016/j.marpol.2019.04.014 (in press).

Eckert, L. E., Ban, N. C., Tallio, S. C., and Turner, N. (2018). Linking marine conservation and indigenous cultural revitalization: first nations free themselves from externally imposed social-ecological traps. Ecol. Soc. 23:23. doi: 10.5751/ES-10417-230423

ESRI (2011). ArcGIS Desktop: Release 10. Redlands, CA: Environmental Systems Research Institute.

Gaydos, J. K., Dierauf, L., Kirby, G., Brosnan, D., Gilardi, K., and Davis, G. E. (2008). Top 10 principles for designing healthy coastal ecosystems like the Salish Sea. EcoHealth 5, 460-471. doi: 10.1007/s10393-009-0209-1
Greene, H. G., Yoklavich, M. M., Starr, R. M., O’Connell, V. M., Wakefield, W. W., Sullivan, D. E., et al. (1999). A classification scheme for deep seafloor habitats. Oceanol. Acta 22, 663-678. doi: 10.1016/S0399-1784(00)88957-4

Hill, J., and Wilkinson, C. (2004). Methods for Ecological Monitoring of Coral Reefs. Townsville, MC: Australian Institute of Marine Science.

Hilty, J., and Merenlender, A. (2000). Faunal indicator taxa selection for monitoring ecosystem health. Biol. Conserv. 92, 185-197. doi: 10.1016/S00063207(99)00052-X

Hughes, S. J. M., Jones, D. O. B., Hauton, C., Gates, A. R., and Hawkins, L. E. (2010). An assessment of drilling disturbance on Echinus acutus var. norvegicus based on in-situ observations and experiments using a remotely operated vehicle (ROV). J. Exp. Mar. Biol. Ecol. 395, 37-47. doi: 10.1016/j.jembe.2010. 08.012

Huntington, H. P. (2000). Using traditional ecological knowledge in science: Methods and applications. Ecol. Appl. 10, 1270-1274. doi: 10.1890/10510761(2000)010[1270:utekis]2.0.co;2

Jenness, D. (2016). The WSÁNEÆE and Their Neighbours: Diamond Jenness on the Coast Salish of Vancouver Island, ed. B. Richling (Oakville, ON: Rock's Mills Press).

Jokiel, P. L., Rodgers, K. S., Brown, E. K., Kenyon, J. C., Aeby, G. S., Smith, W. R., et al. (2015). Comparison of methods used to estimate coral cover in the Hawaiian Islands. Program 3, 1-22. doi: 10.7717/peerj.954

Juanes, J. A., Guinda, X., Puente, A., and Revilla, J. A. (2008). Macroalgae, a suitable indicator of the ecological status of coastal rocky communities in the NE Atlantic. Ecol. Indicat. 8, 351-359. doi: 10.1016/j.ecolind.2007.04.005

Kenyon, J. C., Brainard, R. E., Hoeke, R. K., Parrish, F. A., and Wilkinson, C. B. (2006). Towed-diver surveys, a method for mesoscale spatial assessment of benthic reef habitat: a case study at Midway Atoll in the Hawaiian Archipelago. Coast. Manage. 34, 339-349. doi: 10.1080/08920750600686711

Kroeker, K. J., Kordas, R. L., Crim, R., Hendriks, I. E., Ramajo, L., Singh, G. S., et al. (2013). Impacts of ocean acidification on marine organisms: quantifying sensitivities and interaction with warming. Glob. Chang. Biol. 19, 1884-1896. doi: $10.1111 /$ gcb.12179

Lam, K., Shin, P. K. S., Bradbeer, R., Randall, D., Ku, K. K. K., Hodgson, P., et al. (2006). A comparison of video and point intercept transect methods for monitoring subtropical coral communities. J. Exp. Mar. Biol. Ecol. 333, 115-128. doi: 10.1016/j.jembe.2005.12.009

Lathrop, R. G., Cole, M., Senyk, N., and Butman, B. (2006). Seafloor habitat mapping of the New York bight incorporating sidescan sonar data. Estuar. Coast. Shelf Sci. 68, 221-230. doi: 10.1016/j.ecss.2006.01.019

Lawrence, E., Hayes, K. R., Lucieer, V. L., Nichol, S. L., Dambacher, J. M., Hill, N. A., et al. (2015). Mapping habitats and developing baselines in offshore marine reserves with little prior knowledge: a critical evaluation of a new approach. PLoS One 10:e0141051. doi: 10.1371/journal.pone.0141051

Leonard, G. H., and Clark, R. P. (1993). Point quadrat versus video transect estimates of the cover of benthic red algae. Mar. Ecol. Prog. Ser. 101, 203-208. doi: 10.3354/meps101203

Leujak, W., and Ormond, R. F. G. (2007). Comparative accuracy and efficiency of six coral community survey methods. J. Exp. Mar. Biol. Ecol. 351, 168-187. doi: 10.1016/j.jembe.2007.06.028

Levinton, J. S. (2013). Marine Biology: Function, Biodiversity, Ecology, 4th Edn. Oxford: Oxford University Press.

Magurran, A. E., Baillie, S. R., Buckland, S. T., Dick, J. M. P., Elston, D. A., Scott, E. M., et al. (2010). Long-term datasets in biodiversity research and monitoring: assessing change in ecological communities through time. Trends Ecol. Evol. 25, 574-582. doi: 10.1016/j.tree.2010.06.016

Margules, C. R., and Pressey, R. L. (2000). Systematic conservation planning. Nature 405, 243-253. doi: 10.1038/35012251

Marzinelli, E. M., Williams, S. B., Babcock, R. C., Barrett, N. S., Johnson, C. R., Jordan, A., et al. (2015). Large-scale geographic variation in distribution and abundance of Australian deep-water kelp forests. PLoS One 10:e0118390. doi: 10.1371/journal.pone.0118390

McKechnie, I., Lepofsky, D., Moss, M. L., Butler, V. L., Orchard, T. J., Coupland, G., et al. (2014). Archaeological data provide alternative hypotheses on Pacific herring (Clupea pallasii) distribution, abundance, and variability. Proc. Natl. Acad. Sci. U.S.A. 111, E807-E816. doi: 10.1073/pnas.1316072111

Micallef, A., Le Bas, T. P., Huvenne, V. A. I., Blondel, P., Hühnerbach, V., and Deidun, A. (2012). A multi-method approach for benthic habitat mapping of 
shallow coastal areas with high-resolution multibeam data. Continent. Shelf Res. 39-40, 14-26. doi: 10.1016/j.csr.2012.03.008

Mills, M., Pressey, R. L., Weeks, R., Foale, S., and Ban, N. C. (2010). A mismatch of scales: challenges in planning for implementation of marine protected areas in the Coral Triangle. Conserv. Lett. 3, 291-303. doi: 10.1111/j.1755-263X.2010. 00134.x

Moller, H., Berkes, F., Lyver, P. O., and Kislalioglu, M. (2004). Combining science and traditional ecological knowledge: monitoring populations for comanagement. Ecol. Soc. 9:2. doi: 10.5751/ES-00675-090302

Moller, H., Charleton, K., Knight, B., and Lyver, P. (2009). Traditional ecological knowledge and scientific inference of prey availability: harvests of sooty shearwater (Puffinus griseus) chicks by Rakiura Maori. N. Z. J. Zool. 36, 259-274. doi: 10.1080/03014220909510154

Moore, C. G., Saunders, G., Mair, J. M., and Lyndon, A. R. (2006). The Inauguration of Site Condition Monitoring of Marine Features of Loch Maddy Special Area of Conservation. Scottish Natural Heritage Commissioned Report No. 152 (ROAME No. F02AA409). Edinburgh: Scottish Natural Heritage.

Myers, R. A., and Worm, B. (2003). Rapid worldwide depletion of predatory fish communities. Nature 423, 280-283. doi: 10.1038/nature01610

OpenROV (2017). Berkeley, CA: Open ROV.

Pacunski, R. E., Paulsson, W. A., Greene, H. G., and Gunderson, D. (2008). "Conducting visual surveys with a small ROV in shallow water," in Marine Habitat Mapping Technology for Alaska, eds J. R. Reynolds and H. G. Greene (Fairbanks, AK: Alaska Sea Grant, University of Alaska Fairbanks), 109-128. doi: $10.4027 / \mathrm{mhmta} .2008 .08$

Palardy, J. E., and Witman, J. D. (2011). Water flow drives biodiversity by mediating rarity in marine benthic communities. Ecol. Lett. 14, 63-68. doi: 10.1111/j.14610248.2010.01555.x

Palardy, J. E., and Witman, J. D. (2014). Flow, recruitment limitation, and the maintenance of diversity in marine benthic communities. Ecology 95, 286-297. doi: $10.1890 / 12-1612.1$

Papworth, S. K., Rist, J., Coad, L., and Milner-Gulland, E. J. (2009). Evidence for shifting baseline syndrome in conservation. Conserv. Lett. 2, 93-100. doi: 10.1111/j.1755-263X.2009.00049.x

Parsons, D. M., Shears, N. T., Babcock, R. C., and Haggit, T. (2004). Fine scale habitat change in a marine reserve, mapped using radio acoustically positioned video transects. Mar. Freshw. Res. 55, 257-265.

Pauly, D. (1995). Anecdotes and the shifting baseline syndrome of fisheries. Trends Ecol. Evol. 10:430. doi: 10.1016/S0169-5347(00)89171-5

Pelletier, D., Leleu, K., Mallet, D., Mou-Tham, G., Hervé, G., Boureau, M., et al. (2012). Remote high-definition rotating video enables fast spatial survey of marine underwater macrofauna and habitats. PLoS One 7:e30536. doi: 10.1371/ journal.pone. 0030536

Pressey, R. L., and Bottrill, M. C. (2009). Approaches to landscape- and seascapescale conservation planning: Convergence, contrasts and challenges. ORYX 43, 464-475. doi: 10.1017/S0030605309990500

Rasband, W. (2018). ImageJ. Madison, WI: NIH.

Reef Environmental Education Foundation (2017a). Geographic Zone Report 10 Mile Point. Available online at: http://www.reef.org/db/reports/geo/PAC/ 13470002 (accessed August 19, 2017).

Reef Environmental Education Foundation (2017b). Geographic Zone Report Griffin Island (near Discovery Island). Available online at: http://www.reef.org/ db/reports/geo/PAC/14010003 (accessed August 19, 2017).

Reef Environmental Education Foundation (2017c). Geographic Zone Report South Reef (Discovery Island). Available online at: http://www.reef.org/db/ reports/geo/PAC/14010005 (accessed August 19, 2017).

Richards, L. J. (1986). Depth and habitat distributions of three species of rockfish (Sebastes) in British Columbia: observations from the submersible PISCES IV. Environ. Biol. Fishes 17, 13-21. doi: 10.1007/BF00000397

Riegl, B., Korrubel, J. L., and Martin, C. (2001). Mapping and monitoring of coral communities and their spatial patterns using a surface-based video method from a vessel. Bull. Mar. Sci. 69, 869-880.

Rooper, C. N., and Zimmermann, M. (2007). A bottom-up methodology for integrating underwater video and acoustic mapping for seafloor substrate classification. Continent. Shelf Res. 27, 947-957. doi: 10.1016/j.csr.2006. 12.006
Salas, F., Marcos, C., Neto, J. M., Patrício, J., Pérez-Ruzafa, A., and Marques, J. C. (2006). User-friendly guide for using benthic ecological indicators in coastal and marine quality assessment. Ocean Coast. Manage. 49, 308-331. doi: 10.1016/j. ocecoaman.2006.03.001

Seebens, H., Gastner, M. T., and Blasius, B. (2013). The risk of marine bioinvasion caused by global shipping. Ecol. Lett. 16, 782-790. doi: 10.1111/ele.12111

Shears, N. T. (2007). Biogeography, community structure and biological habitat types of subtidal reefs on the South Island West Coast. N. Z. Sci. Conserv. 281, $5-14$.

Shorezone (2019a). Examples of Use. Available online at: http://www.shorezone. org/examples-of-use (accessed August 29, 2019).

Shorezone (2019b). What is Shorezone and How is the Data Collected? Avilable online at: http://www.shorezone.org/FAQRetrieve.aspx?ID=54122 (accessed August 11, 2019).

Stein, D. L., Tissot, B. N., Hixon, M. A., and Barss, W. (1992). Fish-habitat associations on a deep reef at the edge of the Oregon continental shelf. Fishery Bull. 90, 540-551. doi: 10.1577/1548-8446-3-6

Studio Team, R. (2015). RStudio: Integrated Development for R. Boston, MA: RStudio, Inc.

Suttles, W. P. (1974). The Economic Life of the Coast Salish of Haro and Rosario Straits. New York, NY: Garland Publishing Inc.

Tempera, F., MacKenzie, M., Bashmachnikov, I., Puotinen, M., Santos, R. S., and Bates, R. (2012). "Predictive modeling of dominant macroalgae abundance on temperate island shelves (Azores, Northeast Atlantic)," in Seafloor Geomorphology as Benthic Habitat, eds P. T. Harris and E. Baker (London: Elsevier), 169-184. doi: 10.1016/B978-0-12-385140-6.00008-6

Tissot, B. N. (2007). "Video analysis, experimental design, and database management of submersible-based habitat studies," in Marine Habitat Mapping Technology for Alaska, eds R. Reynolds and H. G. Greene (Fairbanks, AK: Alaska Sea Grant), 157-167. doi: 10.4027/mhmta.20o8.11

Torquato, F., Jensen, H. M., Range, P., Bach, S. S., Ben-Hamadou, R., Sigsgaard, E. E., et al. (2017). Vertical zonation and functional diversity of fish assemblages revealed by ROV videos at oil platforms in The Gulf. J. Fish Biol. 91, 947-967. doi: $10.1111 /$ jfb.13394

van Rein, H., Brown, C. J., Quinn, R., Breen, J., and Schoeman, D. (2011). An evaluation of acoustic seabed classification techniques for marine biotope monitoring over broad-scales $(\& \mathrm{gt} ; 1 \mathrm{~km} 2)$ and meso-scales (10 m2-1 km2). Estuar. Coast. Shelf Sci. 93, 336-349. doi: 10.1016/j.ecss.2011. 04.011

van Rein, H. B., Brown, C. J., Quinn, R., and Breen, J. (2009). A review of sublittoral monitoring methods in temperate waters: a focus on scale. Underw. Technol. 28, 99-113. doi: 10.3723/ut.28.099

VideoLAN (2018). VLC Media Player. Paris. Available online at: https://www. videolan.org (accessed October 11, 2018).

Worm, B., Barbier, E. B., Beaumont, N., Duffy, J. E., Folke, C., Halpern, B. S., et al. (2006). Impacts of biodiversity loss on Ocean ecosystem services. Science 314, 787-790. doi: 10.1126/science.1132294

Yoklavich, M. M., Love, M. S., and Forney, K. a (2007). A fishery-independent assessment of an overfished rockfish stock, cowcod (Sebastes levis), using direct observations from an occupied submersible. Can. J. Fish. Aquat. Sci. 64, 1795-1804. doi: 10.1139/f07- 145

Zavalas, R., Ierodiaconou, D., Ryan, D., Rattray, A., and Monk, J. (2014). Habitat classification of temperate marine macroalgal communities using bathymetric LiDAR. Remote Sens. 6, 2154-2175. doi: 10.3390/rs6032154

Conflict of Interest: The authors declare that the research was conducted in the absence of any commercial or financial relationships that could be construed as a potential conflict of interest.

Copyright (c) 2020 Buscher, Mathews, Bryce, Bryce, Joseph and Ban. This is an openaccess article distributed under the terms of the Creative Commons Attribution License (CC BY). The use, distribution or reproduction in other forums is permitted, provided the original author(s) and the copyright owner(s) are credited and that the original publication in this journal is cited, in accordance with accepted academic practice. No use, distribution or reproduction is permitted which does not comply with these terms. 